\title{
Hacia la protección real de los derechos económicos de los socios minoritarios en sociedades mercantiles no cotizadas*
}

Towards the effective protection of the economic rights of minority shareholders in non - listed companies.

\author{
David EGÜEN SAN MIGUEL \\ Abogado \\ Madrid
}

\begin{abstract}
Resumen: La delicada conjugación de los derechos de todos los socios a rentabilizar sus aportaciones en sociedades mercantiles con los de la propia sociedad o con los de sus acreedores o trabajadores, y el difícil equilibrio de poder en el seno de las sociedades, acarrea importantes conflictos societarios que, en la mayoría de las ocasiones, se terminan judicializando. La falta de concreción al respecto de nuestro Ordenamiento Jurídico hace necesario un mecanismo realmente eficaz que evite el abuso tanto de la minoría como de la mayoría y que garantice la satisfacción del legítimo ánimo de lucro.
\end{abstract}

Este mecanismo viene perfilándose desde hace años con el objeto de ser fieles a la "causa" real de los contratos de sociedad mercantil que ha culminado con el controvertido artículo 348 bis de la Ley de Sociedades de Capital y el artículo 271-6 del non nato Código Mercantil, que irá evolucionando en el futuro hasta garantizar los derechos económicos de los socios de las sociedades mercantiles.

Abstract: The sensitive combination between shareholder's right in order to make profitable their contributions in commercial companies, and those of the

\footnotetext{
* Este artículo obtuvo, el pasado año académico 2019-2020, el Premio Reina María Cristina, en su octava edición, en la modalidad de Derecho. El jurado calificador estuvo conformado por: D. Rafael Navarro-Valls (Presidente), Catedrático de Derecho Eclesiástico del Estado de la UCM, Vicepresidente de la Real Academia de Jurisprudencia y Legislación; D. José Manuel Armada Vadillo (Vocal), es Asesor Jurídico de la Armada y General Auditor; D. Antonio Pau Padrón (Vocal), Abogado del Estado, Notario y registrador de la Propiedad, Secretario de la Real Academia de Jurisprudencia y Legislación, y D. Francisco José Zamora García (Secretario), Decano de Derecho RCU Escorial-María Cristina.
} 
company itself, its creditors or employees; and the delicate balance of power in companies, involve important corporate disputes, which in the majority of cases will end up being judicialized. The lack of specificity of the regulations in this area makes it necessary an effective mechanism to prevent abuse of both the minority and the majority, to ensure the legitimate profit motive.

This mechanism has been outlined for years, in order to be faithful to the real "cause" of mercantile company contracts that has culminated with the controversial article 348 bis of the Law of Corporations, and the non-native article 271-6 of the Mercantile Code, which will evolve over time, to ensuring the economic rights of the Company's partners.

Palabras clave: derecho de separación, dividendos, aplicación del resultado, socio minoritario, artículo 348 bis LSC.

Keywords: separation right, dividends, appropriation of earnings, minority partner, article 348 bis Law of Corporations.

\section{Sumario:}

I. Introducción.

II. Causa del contrato de sociedad mercantil como elemento esencial del mismo.

III. Antecedentes a la regulación actual.

3.1. Antecedentes legislativos.

3.2. Antecedentes jurisprudenciales.

3.3. Antecedentes doctrinales.

IV. Culminación protectora: artículo 348.bis LSC.

4.1. Literalidad del precepto y su inclusión en la Ley.

4.1.1. Aprobación del artículo mediante la Ley 25/2011, de 1 de agosto.

4.1.2. Suspensión y modificación del artículo mediante la Ley $11 / 2018$, de 28 de diciembre. 
4.2. Requisitos para su ejercicio.

4.3. Procedimiento de separación.

4.4. Pérdida de la condición de socio.

4.5. Calificación concursal del crédito derivado del ejercicio del derecho de separación.

4.6. Derecho de arrepentimiento de la sociedad.

4.7. Función del Registrador en la designación del experto independiente.

4.8. Coexistencia con los principios constitucionales.

V. Regulación prevista en el non nato Código Mercantil.

VI. Abusos y dificultad para hallar el punto de equilibrio.

6.1. Abusos de la minoría.

6.2. Equilibrio entre los distintos intereses.

VII. Bibliografía y fuentes. 



\section{INTRODUCCIÓN}

El artículo 116 del Código de Comercio dispone que el contrato de compañía, por el cual dos o más personas, se obligan a poner en fondo común bienes, industria o alguna de estas cosas, para obtener lucro, será mercantil.... En él se recogen los elementos esenciales de las compañías mercantiles que informan el Derecho de Sociedades en España. Por su parte, la doctrina más autorizada, completando la del legislador, la ha definido como la asociación voluntaria de personas que crean un fondo patrimonial común para colaborar en la explotación de una empresa, con ánimo de obtener un beneficio individual, participando en el reparto de las ganancias que se obtengan ${ }^{l}$.

Este trabajo pretende centrarse en uno de los elementos que, durante mucho tiempo, ha quedado supeditado a otros intereses: el ánimo de lucro de los socios -no sólo del de la sociedad misma- y, en especial, el de los minoritarios que son los que, al fin y a la postre, ven violados a menudo sus derechos económicos mientras que sus mayoritarios, a través de diferentes fórmulas -inalcanzables por los primeros- sí rentabilizan sus aportaciones.

\section{CAUSA DEL CONTRATO DE SOCIEDAD MERCANTIL COMO ELEMENTO ESENCIAL DEL MISMO}

Tiene establecido nuestro Ordenamiento Jurídico general, como uno de los elementos esenciales del contrato, la necesidad de "causa" del mismo (art. 1.261 del Código Civil), sin cuya concurrencia, por cierto, podríamos estar ante la liquidación ordenada de la compañía (doctrina de la sociedad de hecho), pues la válida celebración del contrato de sociedad requiere la presencia de los elementos generales de formación del contrato: consentimiento, objeto y causa ${ }^{2}$.

\footnotetext{
${ }^{1}$ URÍA, R., Derecho Mercantil, Ed. Marcial Pons, ${ }^{25} 1998$, p.164.

2 PAZ-AREZ, C., Las sociedades mercantiles, en MENÉNDEZ, A. (coord.), Lecciones de Derecho Mercantil, Ed. Thomson Civitas ${ }^{3}$ 2005, p. 229.
} 
Pues bien, dejando sentada la imperativa necesidad de hallar una causa para suscribir un contrato de constitución de una sociedad (o de entrada de socios en una ya constituida por medio de una ampliación de capital), ésa no puede ser otra que el ánimo de lucro de los socios que aportan recursos de cualquier género evaluables económicamente (artículo 61 y ss. de la Ley de Sociedades de Capital). Esta identificación de la causa del contrato con el ánimo de lucro del socio se prevé igualmente en el citado artículo 116 del Código de Comercio, el cual se obtiene mediante el desarrollo del objeto social, pues éste no es, ni puede ser, la finalidad per se que mueve a los socios.

Concordando con el artículo 116 del Código de Comercio de 1885, la afectio societatis vuelve a recogerse en el artículo 1.665 del Código Civil de 1889 al positivizar sin ningún género de dudas el ánimo de repartir entre sí las ganancias por los socios en las sociedades civiles.

En suma, de lo previsto en los artículos citados se desprende, en palabras del catedrático de la Universidad de Sevilla, José Carlos Vázquez Cueto, que la distribución de cantidades en concepto de participación en ganancias constituye el fin natural de la participación del accionista en la sociedad", , al entender como una predisposición del legislador el reparto de las ganancias sociales de forma ordinaria debido, precisamente, a la causa lucrativa del contrato social.

Por su parte, el profesor Cándido Paz-Ares afirmaba que en la sociedad, la causa es el fin común que persiguen las partes. (...) el fin común se compone de dos subelementos: el fin común último o abstracto y el próximo o concreto. El fin común último es normalmente, aunque no necesariamente, el ánimo de lucro. El fin próximo es el objeto social, esto es, la actividad que se ha programado desarrollar para la consecución del fin común (por ej. la producción de energía eléctrica, la venta de calzado, la fabricación de muebles, etc.). Ambos elementos son inseparables, pues ninguno de ellos es capaz por sí mismo de llenar la causa del contrato de sociedad ${ }^{4}$.

Precisamente por la coexistencia de esas dos finalidades, que han de conjugarse con la situación y la estrategia de cada empresa, la Ley otorga la decisión de determinar la aplicación del resultado a la Junta General (artículo 273 de la Ley de Sociedades de Capital). A la situación y a la estrategia, hay

\footnotetext{
3 "La sociedad anónima: las cuentas y la documentación contable en la sociedad anónima", en OLIVENCIA, M.; FERNÁNDEZ-NÓVOA, C., y JIMÉNEZ DE PARGA, R. (dir.), Tratado de Derecho Mercantil, Ed. Marcial Pons, 2001, pp. 291 y ss.

4 "Las sociedades mercantiles", MENÉNDEZ, A., Lecciones de Derecho Mercantil, Ed. Thomson Civitas, ${ }^{3} 2005$, p. 234.
} 
que añadir asimismo la salvaguarda de los intereses de otros operadores mercantiles, como los acreedores o sus trabajadores.

Así las cosas, no puedo coincidir con los numerosos y autorizados autores que, como el catedrático de la Universidad Carlos III, Rafael Illescas Ortiz, defienden que esas previsiones legales no son suficientes para que un socio pueda reclamar el reparto de dividendos con cargo a las ganancias sociales repartibles, sobre todo cuando no existen razones que justifiquen la dotación de reservas voluntarias.

Por el contrario, me uno al profesor Rodrigo Uría, que considera que no se puede creer que el derecho abstracto a participar en las ganancias sea un derecho vacio de sustancia. Protege al accionista, por el contrario, contra cualquier posible acuerdo social que pretenda excluirle de la participación en los beneficios obtenidos por la empresa y contra la posible decisión de la mayoría de no repartir los beneficios que se vayan obteniendo, reservándolos indefinidamente. La sociedad puede constituir reservas voluntarias sustrayendo al reparto de una parte de los beneficios de cada ejercicio, e incluso podrá suspender totalmente el reparto de dividendos si las necesidades de la empresa asi lo exigen; pero no podrá negarse sistemáticamente a repartir las ganancias arrojadas por los balances, porque ello iría contra la finalidad perseguida por los socios al constituirse en sociedad. Añade precisamente Uría, a la hora de explicar la definición de sociedad mercantil que se reprodujo en la Introducción de este trabajo, que precisamente ese ánimo de lucro hace que no puedan considerarse verdaderas sociedades mercantiles aquellas uniones de personas que no persigan un fin económico lucrativo (v Res. D.G.R. de 2 de febrero de 1966) o que, aun procurando la obtención de ganancias, no se proponga la distribución de éstas entre los coasociados ${ }^{6}$.

Por su parte, los profesores Fernando Sánchez Calero y Juan SánchezCalero Guilarte ${ }^{7}$, abogan, igualmente, porque el derecho reconocido en el artículo 93.a) de la Ley de Sociedades de Capital sí comprende el derecho al dividendo anual siempre que no exista disposición estatutaria en contra ni circunstancias económicas que hagan aconsejable a la Junta General la dotación de reservas voluntarias, de modo que si se deniega la distribución de dividendos sin que, en efecto, concurran circunstancias concretas y objetivas, podría ser objeto de impugnación pues el artículo 273 de la Ley de Sociedades de

\footnotetext{
5 "El derecho del socio al dividendo hoy: un apunte", en Revista de Derecho de los Negocios, $\mathrm{n}^{\circ} 21$ (junio 1992) 21 y ss.

${ }^{6}$ Derecho Mercantil, Ed. Marcial Pons, ${ }^{25} 1998 .$, pp. 270 y 165.

${ }^{7}$ Instituciones de Derecho Mercantil, Ed. Thomson Aranzadi, ${ }^{30} 2007$, Vol. I, pp. 400 y ss. y 562 y ss.
} 
Capital no justifica arbitrariedad o abuso de derecho (artículo 7 del Código Civil). Esto es: la libertad para acordar la distribución del resultado no es absoluta, máxime cuando pueden darse situaciones de "abuso de mayoría" en las que los socios mayoritarios busquen burlar sistemáticamente los derechos económicos de los minoritarios canalizando rendimientos de la sociedad por vías como la retribución de administradores o la prestación de servicios profesionales.

En este sentido, afirman los profesores Sánchez Calero y Sánchez-Calero Guilarte: especial motivo de impugnación existirá si el acuerdo intenta favorecer los intereses de un grupo de socios, pues es de interés social el reparto de dividendos, ya que es común a todos los socios.

Desafortunadamente, tales conflictos societarios, que tensionan gravemente el clima interno de las compañías, son enormemente frecuentes y, a menudo, los asesores jurídicos que operamos en estos ámbitos, lidiamos con la falta de exhaustividad de nuestra legislación, la heterogeneidad de la doctrina científica y la singularidad de las resoluciones judiciales dictadas al respecto, todo ello perfectamente comprensible cuando la dificultad de alcanzar un equilibrio entre los diferentes intereses es tan acusada.

En consonancia con todo lo anterior, tanto la doctrina como la jurisprudencia han basculado mayoritariamente hacia la teoría contractualista de las sociedades mercantiles frente a la institucionalista.

Por su parte, el Tribunal Supremo ha venido defendiendo la concepción contractual del interés social entendiéndolo como la suma de los particulares de los socios que pueden verse defraudados, por ejemplo, en caso de no reparto de dividendos. En este sentido, su conocida Sentencia de 19 de febrero de 1991 afirma: en torno a la idea o concepto del interés social existen dos teorías completamente opuestas: la institucionalista, que considera a la sociedad anónima como una institución-corporación, en la que el interés social que alli se persigue, es distinto del de sus socios, viniendo a coincidir con los intereses de los componentes de la empresa (accionistas, administradores, acreedores, trabajadores, etc.); y la teoría contractualista, consagrada en nuestra legislación, según la cual el interés social no es otro que la suma de los intereses particulares de sus socios, de forma que cualquier daño producido en el interés común del reparto de beneficios, o en cualquier otra ventaja comunitaria, supone una lesión al interés social ${ }^{8}$.

\footnotetext{
${ }^{8}$ Criterio reiterado invariablemente en SSTS de 18 de septiembre de 1998, 4 de marzo de 2000, 29 de noviembre de 2002, 7 de marzo de 2006 y ATS de 17 de abril de 2006.
} 


\section{ANTECEDENTES A LA REGULACIÓN ACTUAL}

\subsection{Antecedentes legislativos}

En suma, partiendo de la base de que la razón de ser de la constitución y/o participación en las sociedades es la creación de riqueza para los socios, se impone buscar un mecanismo que proteja precisamente esos derechos económicos, teniendo el legislador $-\mathrm{y}$ el resto de operadores jurídicos- la ardua tarea de neutralizar los abusos de derecho tanto de las mayorías como de las minorías y de compatibilizar los intereses, entre otros, de socios, acreedores y trabajadores.

Así, con anterioridad a las controvertidas Leyes 25/2011 y 11/2018, cuya aprobación será posteriormente abordada con detenimiento, se pretendieron positivizar mecanismos protectores de los derechos económicos de los socios.

Mediante el Anteproyecto de Ley de reforma de la Ley de Sociedades de Responsabilidad Limitada de 1994, se pretendió introducir el contenido de su artículo 87, titulado reparto obligatorio de dividendos con el objeto de prever una minoría cualificada capaz de exigir el reparto de dividendos. En este sentido, la Exposición de Motivos III del Anteproyecto afirmaba: entre las ideas rectoras de la Ley destaca la de una más intensa tutela del socio y de la minoría. Esta tutela es particularmente necesaria en una forma social en la que, por su carácter cerrado, falta la más eficaz medida de defensa: la posibilidad de negociar libremente en el mercado el valor patrimonial en que se traduce la participación del socio. Este es el sentido del derecho al reparto anual obligatorio de un mínimo de las ganancias sociales, de la amplitud con que se admite el derecho de separación del socio (...).

Así, este precepto ${ }^{9}$, que no fue incorporado finalmente, preveía:

A partir del tercer año a contar desde la constitución o desde la transformación en sociedad de responsabilidad limitada, la sociedad estará obligada a distribuir como dividendo un tercio, al menos, de los beneficios legalmente repartibles obtenidos durante el ejercicio social, siempre que, antes de la aprobación de las cuentas anuales, lo soliciten socios que representen al menos un cinco por ciento del capital social.

${ }^{9}$ El artículo 87, junto con el resto del Anteproyecto de Ley fue redactado por una Ponencia especial integrada por los reputados Juan Luis Iglesias Prada, Francisco Núñez Lagos, Ángel Rojo Fernández-Ríos y Heliodoro Sánchez Rus; texto posteriormente revisado y aprobado por el Pleno de la Sección de Derecho Mercantil de la Comisión General de Codificación, presidida por Aurelio Menéndez Menéndez y actuando como Secretario Jesús Sebastián Lorente. 
Hágase notar que la versión elevada por la Ponencia al Pleno de la Sección de Derecho Mercantil de la Comisión General de la Codificación no preveía requerimiento previo de la minoría garantizando un reparto anual, sólo sorteado con la unanimidad de los socios.

Sin embargo, esta norma, como se ha dicho, no fue aprobada y quedó al margen de la Ley 2/1995, de 23 de marzo, de Sociedades de Responsabilidad Limitada.

Años después, en 2002, la Sección de lo Mercantil de la Comisión General de la Codificación, en el marco de los trabajos para la aprobación de un Código de Sociedades Mercantiles -que nunca llegó a ver la luz, ni siquiera como anteproyecto de ley-, proponía la aprobación de un precepto con un contenido prácticamente idéntico al controvertido artículo 348 bis; el artículo 150, que preveía:

1. Salvo disposición contraria de los estatutos sociales, a partir del quinto ejercicio a contar desde la constitución, el socio de cualquier clase de sociedad mercantil tendrá derecho a separarse de la sociedad en el caso de que no se acordara la distribución de, al menos, un tercio de los beneficios legalmente repartibles obtenidos durante el ejercicio social anterior.

2. El plazo para el ejercicio del derecho de separación será de un mes a contar desde la fecha en que se hubiera celebrado o hubiera debido celebrarse la Junta general ordinaria de socios.

3. Lo dispuesto en este artículo no será de aplicación a los socios de las sociedades de interés económico.

Desafortunadamente, aquella propuesta de Código de Sociedades Mercantiles de 2002, junto con su artículo 150, tampoco fue incorporado a nuestro Ordenamiento Jurídico.

En todo caso, hacer notar, como una de las diferencias más destacables respecto del Anteproyecto de 1994, que los expertos de la Comisión codificadora previeran la posibilidad de su neutralización mediante disposición estatutaria en contra, lo cual sí podría haber sido conveniente siempre y cuando, para esta reforma estatutaria, se previeran mayorías reforzadas suficientes -o incluso la proscrita unanimidad- para garantizar el consenso real de los socios o se permitiera igualmente el derecho de separación al estilo de los previstos en el artículo 346 de la Ley de Sociedades de Capital, al alterarse la causa misma que justificó la entrada de los socios en el capital de la compañía. 
En este sentido, la profesora Aurora Campins Vargas aboga por que cuando una regulación estatutaria condicione el ejercicio de este derecho a la mejor defensa del interés patrimonial de la sociedad debería admitirse siempre que se acuerde con el consentimiento de todos los socios con el objeto de impedir que los socios acaben por convertirse en prisioneros del título ${ }^{10}$, máxime en sociedades cerradas cuyas participaciones, en la práctica, son ilíquidas.

\subsection{Antecedentes jurisprudenciales}

El alcance de los derechos económicos del socio, reconocidos por todas las leyes societarias que se han ido sucediendo desde la 14/1953, de 17 de julio, de Sociedades de Responsabilidad Limitada, siempre han recogido como uno de los derechos de los socios -el primero de ellos en ser enumerado- el de la percepción de dividendos, aunque impreciso y sometido al acuerdo concreto de la Junta General, lo que ha llevado a que esta cuestión fuera constantemente discutida en nuestros Tribunales cuando la mayoría del capital, que generalmente ocupa la administración de la compañía, se obstina en destinar los beneficios sociales durante una serie de ejercicios a dotar reservas voluntarias, percibiendo simultáneamente retribuciones a las que tampoco tiene acceso la minoría.

La jurisprudencia ha venido respaldando mayoritariamente ${ }^{11}$ la competencia de la Junta General para determinar el destino de los beneficios potencialmente repartibles -extremo que resulta indiscutible teniendo en cuenta que se trata de una facultad concedida expresamente por la Ley- entendiendo que su atesoramiento en la compañía no es abusivo.

Sin embargo, también se han dictado resoluciones que consideran que ese atesoramiento repetido e injustificado acarrea, de hecho y necesariamente, la privación a los socios minoritarios a participar en los beneficios; así, Sentencias como la de la Audiencia Provincial de Madrid de 5 de octubre de 2005, consideran que el derecho abstracto al dividendo permitirá ejercitar acción contra acuerdos sociales que veden sistemáticamente o sin justificación alguna el reparto de beneficios en favor de los accionistas, como derecho esencial de la propia acción. (...) Si injustificadamente no se repartiese el dividendo, sería posible impugnar el acuerdo social ex art. 115 del propio texto refundido por ser contrario a la Ley.

10. "Derecho a la separación por no reparto de dividendos: ¿es un reparto disponible por los socios?", en Revista Jurídica Española de Doctrina, Jurisprudencia y Bibliografía, 7824 (de 23 de marzo de 2012) 7 y ss.

11. SSTS 30 de noviembre de 1979, 10 de octubre de 1996 o 19 de marzo de 1997; y SSAP de Barcelona de 25 de julio de 1994, de Zaragoza de 13 de julio de 2005 o de Alicante de 15 de julio de 2010. 
Por su parte, la Audiencia Provincial de Valencia, en sus Sentencias de 5 de junio y 15 de septiembre de 1997 -con idéntica argumentación pues los hechos y, en cierta medida, también las partes, eran los mismos-, entiende abusivo el acuerdo adoptado por la mayoría de la Junta General de destinar la práctica totalidad de las ganancias sociales a reservas voluntarias apoyándose tanto en la sucesión de acuerdos de no reparto de dividendos -ni en la ínfima proporción, pese a ser cuantiosas las ganancias- cuanto en la composición de la mercantil demandada (...).

Igualmente, es importante resaltar la nula importancia que le otorga la Audiencia al hecho de que el demandante (socio minoritario cuyos derechos económicos, decía, se habían lesionado) hubiera votado a favor de la dotación de reservas en ejercicios precedentes; a este respecto afirma: tampoco puede ser argumento en contra el hecho de que el Sr. Braulio suscribió los acuerdos anteriores en tal sentido, pues, aun admitiéndolo, no tiene por qué ser una actitud uniforme y vinculante en el futuro, al devenir, con posterioridad, el cambio de circunstancias pérdida de su condición de miembro del consejo y de su trabajo, coetáneas, en mayor o menor medida, al acuerdo controvertido, para concluir que ha existido fraude de normas legales y principios generales imperantes en una sociedad de tipo capitalista al haberse adoptado el acuerdo de no reparto de dividendos de modo sistemático y sin causa legal o razonable para ello y con falta de buena fe.

Por su parte, las Audiencias Provinciales de Álava y Baleares abundan en la exigencia de razones objetivas y fundadas para no repartir dividendos en sus Sentencias de 19 de octubre de 2010 y 22 de diciembre de 2010, respectivamente; de hecho, la de Álava, siguiendo las Sentencias del Tribunal Supremo de 26 de mayo de 2005 y 10 de octubre de 1996 afirma que privar al socio minoritario, sin causa acreditada alguna, de sus derechos a percibir los beneficios sociales obtenidos y proceder a su retención sistemática, se presenta a todas luces como una actuación abusiva, que no puede obtener el amparo de los Tribunales, pues se trata de una actitud impeditiva afectada de notoria ilicitud (...) pues todo ello significaría consagrar un imperio despótico de la mayoría”. En el supuesto concreto de los autos, se estima que la dotación de reservas voluntarias resulta "injustificada.

Además, la Sentencia de 19 de octubre de 2010, en relación con la discrecionalidad empresarial afirma que si bien puede constituir un argumento incluso de política empresarial, sin embargo no se acredita en la dimensión necesaria para justificar la limitación del derecho a participar en los beneficios, dentro del margen que la Junta razonablemente considere oportuna, pues lo irregular es precisamente esa limitación íntegra, no la aplicación equilibrada y razonable 
de los beneficios para reservas voluntarias, (...) más si como aquí acontece en el supuesto de autos el actor no participa con su trabajo en la sociedad y no percibe retribuciones laborales o comerciales (...), mientras que otros socios sí participan o han participado de la relación laboral retribuida.

Por su parte, la Audiencia Provincial de Barcelona, en su Sentencia de 21 de enero de 2011, tras abordar curiosas disquisiciones respecto a la utilización de dinero negro -según reconoce sorprendentemente el propio Administrador de la compañía en el acto del Juicio- para proceder al pago de socios, y tras reconocer el carácter abstracto del derecho al dividendo hasta que la Junta adopte el acuerdo correspondiente, puntualiza la existencia de límites a la forma en la que la mayoría puede imponer su criterio a la minoría en el ejercicio de los derechos soberanos de la juntas de socios. Estos límites proceden de lo que establece el artículo 7 del Código Civil, que establece que el ejercicio de los derechos se realice de acuerdo con las exigencias de la buena fe (apartado 1) y proscribe el abuso de derecho (apartado 2).

Por lo que respecta al número de ejercicios sociales en los que la Junta debe decidir la dotación de reservas voluntarias para encontrarnos ante un abuso de derecho frente a minoritarios, la Audiencia Provincial de Madrid, en sus Sentencias de 30 de enero y 24 de septiembre de 2009, entiende que durante tres ejercicios seguidos se haya acordado la aplicación a reservas de los beneficios sociales no supone, a juicio de esta Sala (...), un abuso de derecho, pues consideramos que no se trata de un número sucesivo de ejercicios sociales suficientemente significativo como para revelar un sistemático bloqueo de carácter abusivo.

Aludir igualmente por su claridad la Sentencia del Juzgado de Primera Instancia $\mathrm{n}^{\circ} 23$ de Madrid de 21 de diciembre de 2000. En ella, se deja sentado: el fin que persigue el contrato de sociedad no es otro que obtener lucro, o dicho de otro modo, el interés que guía a las partes al constituir la sociedad, o al entrar a formar parte de ella a través de la compra de acciones, no es otro que obtener un reparto anual de beneficios siempre que ello no perjudique la actividad futura de la empresa en lo que también tiene interés, porque, de tener que esperar hasta la liquidación de la sociedad para participar en el patrimonio resultante, no quedaría satisfecho su ánimo de lucro. En este sentido, (...) se podría decir que, de acuerdo con una moderna corriente doctrinal, el accionista tiene el derecho al reparto anual de las ganancias sociales siempre que, de forma excepcional, la situación económica y financiera de la sociedad no aconseje lo contrario porque si no acabará siendo ilusorio ese derecho a participar en las ganancias sociales que la ley eleva, implícitamente, a la más alta categoría dentro de los derechos del tenedor de acciones. 
Resulta obligado citar finalmente la ya aludida Sentencia de 26 de mayo de 2005 del Tribunal Supremo, resolución ampliamente criticada por la doctrina principalmente por su escasa fundamentación-. Únicamente esta Sentencia (que confirma la de Primera Instancia y la de apelación) ha optado por acordar el reparto de dividendos suplantando las competencias conferidas ex lege a la Junta General.

\subsection{Antecedentes doctrinales}

Además de por la jurisprudencia y por algunos expertos codificadores, la necesidad de proteger al minoritario de la injustificada y reiterada dotación de reservas voluntarias ya había sido denunciada por un sector de la doctrina.

Por lo que respecta a esta breve reseña doctrinal anterior al reconocimiento legal y expreso del derecho de separación por no distribución de dividendos, resulta obligado comenzar aludiendo a la obra del profesor Neila Hernández ${ }^{12}$, que sirve de inspiración precisamente al artículo 87 del Anteproyecto de Ley de Responsabilidad Limitada de 1994 que preveía el reparto de un dividendo mínimo como protección de los minoritarios frente al abuso de la mayoría.

Precisamente este artículo -el 87 del Anteproyecto- es calificado de "muy positiva norma" por el referente profesor Ángel Rojo Fernández-Ríos, miembro de la Ponencia especial redactora del Anteproyecto, al entender que como enseña la experiencia, no es infrecuente en las sociedades cerradas que la mayoría -que obtiene de la propia sociedad otras vías de rentabilidad de su inversión (los denominados "dividendos encubiertos")- siga una política de no reparto de los resultados obtenidos creciendo así la conflictividad interna de la sociedad ${ }^{13}$. Concluye el catedrático Rojo Fernández-Ríos afirmando que esta obligación de reparto anual, sea en la versión de la Ponencia, sea en la versión del Anteproyecto de Ley, debería reintroducirse en el articulado como un medio prudente para fortalecer el contenido económico de la posición jurídica del socio, a la vez que, para disminuir el grado de conflictividad interna en esta forma social.

Por su parte, el profesor Fernando Martínez Sanz reflexiona en 1996 diciendo que no parece que deba plantear duda alguna, en este sentido, configurar como

\footnotetext{
${ }^{12}$ La Ley de Sociedades de Responsabilidad Limitada de 1995. Doctrina, jurisprudencia y Directivas Comunitarias, Ed. Civitas, Universidad de Jaén, p. 1904.

13 "La sociedad de responsabilidad limitada: problemas de política y técnica legislativas", en BONARDELL LENZANO, R.; MEJÍAS GÓMEZ, J., y NIETO CAROL, U. (coords.), La Reforma de la Sociedad de Responsabilidad Limitada, Ed. Dyckinson, 1994, p. 75.
} 
causa de separación cualquier modificación estatutaria, u otras hipótesis que tengan como presupuesto un acuerdo social que produzca una mutación sensible de las condiciones iniciales. (...) Tampoco sería aventurado reconocer idéntico derecho, por ejemplo, en ciertos supuestos que, aun no implicando una alteración de la estructura de la sociedad, puedan producir en el socio minoritario una vinculación que se considere opresiva. Estoy pensando en situaciones prolongadas de ausencia de reparto de dividendos, pese a existir ganancias (circunstancia, por otra parte, que se da con bastante frecuencia en sociedades medianas y pequeñas, en donde los socios mayoritarios obtienen rendimientos de la sociedad a través de vías distintas de la percepción de dividendos), llegando a afirmar que no cabe descartar que se reconozca estatutariamente al socio disidente el derecho de separarse de la sociedad cuando ésta decida no repartir dividendos durante una serie de ejercicios consecutivos (tres o más, por ejemplo), pese a existir ganancias ${ }^{14}$.

\section{CULMINACIÓN PROTECTORA: ARTÍCULO 348.BIS LSC}

\subsection{Literalidad del precepto y su inclusión en la Ley}

\subsubsection{Aprobación del artículo mediante la Ley 25/2011, de 1 de agosto}

Con independencia de los intentos codificadores de positivizar el derecho de separación en situaciones de conflicto permanente entre minoritarios y mayoritarios derivados del bloqueo de las ganancias sociales en la compañía, la doctrina venía denegando esa posibilidad al entender que no se podía incardinar en ninguno de los previstos en la Ley ${ }^{15}$-o en los estatutos- haciéndose imprescindible su inclusión expresa en la Ley de Sociedades de Capital.

El artículo 348 bis, cuyo encabezamiento es Derecho de separación en caso de falta de distribución de dividendos, fue introducido mediante enmienda del Grupo Parlamentario Popular en el trámite parlamentario de aprobación de la citada Ley $25 / 2011$, de 1 de agosto ${ }^{16}$, alegando que el derecho del socio

${ }^{14}$ MARTÍNEZ SANZ, F., "Causas de separación del socio en la Ley de Sociedades de Responsabilidad Limitada", en Revista de Derecho de Sociedades, Año IV, no 6 (1996) 62.

${ }^{15}$ Coincido con los autores que han venido defendiendo la existencia de una causa legal no escrita de separación por justos motivos en nuestro Ordenamiento Jurídico, pues no habría razón alguna para no reconocer, tras una aplicación extensiva y analógica, el derecho de separación al supuesto en el que no le sea exigible a un socio su permanencia en la sociedad o no pueda transmitir su participación en el mercado (Jesús Alfaro, Aurora Campins, Francisco Javier Framiñán Santas, etc.).

${ }^{16}$ Ley 25/2011, de 1 de agosto, de reforma parcial de la Ley de Sociedades de Capital e incorporación de la Directiva 2007/36/CE del Parlamento Europeo y del Consejo, de 11 de julio, sobre determinados derechos de los accionistas de sociedades cotizadas. 
a las ganancias sociales se vulnera frontalmente si, año tras año, la Junta General, a pesar de existir beneficios, acuerda no repartirlos. La Propuesta de Código de Sociedades Mercantiles, de 2002 (art. 150), ya incluyó una norma semejante a la que este Grupo propone introducir en la Ley de Sociedades de Capital a fin de hacer efectivo ese derecho. La falta de distribución de dividendos no sólo bloquea al socio dentro de la sociedad, haciendo ilusorio el propósito que le animó a ingresar en ella, sino que constituye uno de los principales factores de conflictividad. El reconocimiento de un derecho de separación es un mecanismo técnico muy adecuado para garantizar el reparto parcial periódico y para reducir esa conflictividad. Con esta solución se posibilita el aumento de los fondos propios, permitiendo que las sociedades destinen dos tercios de esas ganancias a la dotación de reservas, y se satisface simultáneamente la legítima expectativa del socio.

De este modo, la enmienda que introducía en la Ley de Sociedades el artículo 348 bis fue incorporado al texto del proyecto por unanimidad de todos los Grupos Parlamentarios, quedando fijado con el siguiente tenor literal:

Artículo 348.bis. Derecho de separación en caso de falta de distribución de dividendos.

1. A partir del quinto ejercicio a contar desde la inscripción en el Registro Mercantil de la sociedad, el socio que hubiera votado a favor de la distribución de los beneficios sociales tendrá derecho de separación en el caso de que la junta general no acordara la distribución como dividendo de, al menos, un tercio de los beneficios propios de la explotación del objeto social obtenidos durante el ejercicio anterior, que sean legalmente repartibles.

2. El plazo para el ejercicio del derecho de separación será de un mes a contar desde la fecha en que se hubiera celebrado la junta general ordinaria de socios.

3. Lo dispuesto en este artículo no será de aplicación a las sociedades cotizadas.

A esta redacción, justamente criticada por los autores en la mayoría de los casos, se le puede reprochar la clara divergencia entre lo pretendido por el legislador -la protección del minoritario aparentemente sólo frente al abuso de la mayoría, como se justifica en la enmienda- y el efecto práctico alcanzado ya que parece presuponer que la falta de reparto constituye per se una situación de abuso $^{17}$. Lo congruente con la justificación de la enmienda hubiera sido la

${ }^{17}$ CAMPINS VARGAS, A., y ALFARO ÁGUILA-REAL, J., Abuso de la mayoría en el reparto de dividendos y derecho de separación del socio en las sociedades de capital., Civitas, 2014. 
introducción de la obligación de repartir dividendos como regla general, pudiendo los Administradores proponer aplicar las ganancias a reservas cuando acrediten justos motivos (tensiones financieras, emprendimiento de importantes inversiones, etc.) manteniendo el derecho de separación como último medio para zanjar los conflictos societarios entre socios, como defiende el propio catedrático Fernando Martínez Sanz ${ }^{18}$. A cambio, vaciando -o mejor dicho: coartando-, en cierta medida, la competencia de la Junta General para, atendiendo los intereses de todos los actores sociales, decidir sobre la aplicación de resultado, el legislador ha habilitado el medio para la separación libre del socio en caso de que, en cualquier escenario, no se produzca reparto de dividendos.

Por su parte, será la Audiencia Provincial de Zaragoza la que recupere la idea de lucro con el que comenzábamos este estudio en su Sentencia 380/2018 de 17 de mayo de 2018 (Rec. 486/2018) que afirma:

Es un precepto que trata de recuperar (según amplio sector doctrinal) la idea de lucro. Que los beneficios del ejercicio del objeto social han de repercutir en los socios; en todos. Pues esa es la finalidad última de una sociedad.

Por ello, con independencia de la decisión de la mayoría sobre el destino de los beneficios, este precepto busca evitar el abuso del socio mayoritario, permitiendo al minoritario separarse de la sociedad, obteniendo el valor de sus acciones o participaciones.

En cualquier caso, desde su aprobación, este precepto se mantuvo suspendido mediante la Ley 1/2012, de 22 de junio, el Real Decreto-ley 11/2014, de 5 de septiembre y la Ley $9 / 2015$, de 25 de mayo, que introdujeron y mantuvieron una vacatio legis hasta el 31 de diciembre de 2016 sin ningún tipo de justificación en sus respectivas Exposiciones de Motivos aunque pareciera que el legislador pretendía salvaguardar el fortalecimiento patrimonial de las sociedades en un contexto de crisis económica.

4.1.2. Suspensión y modificación del artículo mediante la Ley 11/2018, de 28 de diciembre

La polémica doctrinal levantada por la introducción del artículo 348 bis en la Ley de Sociedades de Capital, su aplicación práctica y el momento económico del país, hizo que se comenzara a reclamar su modificación, que terminó

\footnotetext{
18 "Causas de separación del socio en la Ley de Sociedades de Responsabilidad Limitada", en FERNANDO MARTÍNEZ SANZ, F., Revista de Derecho de Sociedades, no 6 (1996) 27 y ss.
} 
concretando el grupo parlamentario de la antigua Convergència i Unió mediante la presentación de una proposición no de ley el 21 de febrero de 2012 -apenas cuatro meses después de su entrada en vigor- con el objeto de reformar el precepto para superar la neutralidad de su literalidad y circunscribir el derecho de separación en caso de no reparto de dividendos a aquellos supuestos en los que existiera verdadero abuso de derecho por la mayoría sin olvidar la protección de otros intereses, como los de la propia sociedad o sus acreedores.

En suma, la propia proposición pretendía que ni la distribución como dividendo de un tercio de los beneficios del ejercicio a partir del quinto año de constitución de la sociedad ni, en su caso, el ejercicio del derecho de separación por su no distribución, sitúen a ninguna sociedad no cotizada en causa de reducción de capital o de disolución obligatorias o en situación de insolvencia, actual o inminente, conlleven el incumplimiento de las obligaciones que la sociedad haya contraído con terceros, o dificulten o pongan en entredicho la viabilidad de estas empresas.

En el debate suscitado al respecto en el Congreso de los Diputados, se puso de manifiesto por los distintos portavoces parlamentarios la necesidad de evitar propiciar ahora abusos de la minoría, permitir la neutralización o modificación vía estatutos de esta materia o de conjugar los derechos de los socios con los de las propias sociedades, máxime en contextos de crisis económicas.

Todo ello llevó a que los grupos parlamentarios popular, socialista y de UPyD aprobaran una proposición en la que instaban al Gobierno a tener en cuenta esos extremos en sus estudios de creación de un Código Mercantil que se encontraba componiendo los Ministerios de Justicia y de Economía y Competitividad.

Asimismo, mediante las enmiendas 13 y 14 de 21 de mayo de 2012, el grupo parlamentario de Convergència i Unió propuso la inclusión de la posibilidad de disposición en contrario de los estatutos sociales, el reparto de un dividendo razonable -en vez de un tercio- que no perjudique el interés social, así como la suspensión de aplicación del artículo 348 bis de la Ley de Sociedades de Capital hasta el 31 de diciembre de 2014.

Disiento de esta iniciativa parlamentaria toda vez que la posibilidad de regulación estatutaria del derecho de separación no lleva aparejada el establecimiento de un régimen de mayorías especial, la introducción de un término difuso y subjetivo (dividendo razonable), que añadiría aún más inseguridad, y la suspensión de aplicación del precepto, con el consiguiente paso atrás en la protección de los derechos económicos de los socios minoritarios. 
En todo caso, las Cortes aprobaron la suspensión del artículo 348 bis mediante la Ley $1 / 2012$, de 22 de julio, de simplificación de las obligaciones de información y documentación de las fusiones y escisiones de sociedades de capital, en cuya Disposición Transitoria se preveía la paralización de efectos hasta el 31 de diciembre de 2014; siendo prorrogada hasta el 31 de diciembre de 2016 por la Disposición Final Primera de la Ley 9/2015, de 25 de mayo, de medidas urgentes en materia concursal y del Real Decreto Ley 11/2014, de 5 de septiembre, de medidas urgentes en materia concursal.

Pues bien, la literalidad del artículo 348 bis de la Ley de Sociedades de Capital permaneció en vigor hasta el 29 de diciembre de 2018 al entrar en vigor el 30 de diciembre la reforma introducida por la Ley 11/2018, de 28 de diciembre, por la que se modifica el Código de Comercio, el texto refundido de la Ley de Sociedades de Capital aprobado por el Real Decreto Legislativo 1/2010, de 2 de julio, y la Ley 22/2015, de 20 de julio, de Auditoría de Cuentas, en materia de información no financiera y diversidad.

Así, la redacción del artículo 348 bis actualmente vigente es la siguiente:

1. Salvo disposición contraria de los estatutos, transcurrido el quinto ejercicio contado desde la inscripción en el Registro Mercantil de la sociedad, el socio que hubiera hecho constar en el acta su protesta por la insuficiencia de los dividendos reconocidos tendrá derecho de separación en el caso de que la junta general no acordara la distribución como dividendo de, al menos, el veinticinco por ciento de los beneficios obtenidos durante el ejercicio anterior que sean legalmente distribuibles siempre que se hayan obtenido beneficios durante los tres ejercicios anteriores. Sin embargo, aun cuando se produzca la anterior circunstancia, el derecho de separación no surgirá si el total de los dividendos distribuidos durante los últimos cinco años equivale, por lo menos, al veinticinco por ciento de los beneficios legalmente distribuibles registrados en dicho periodo.

Lo dispuesto en el párrafo anterior se entenderá sin perjuicio del ejercicio de las acciones de impugnación de acuerdos sociales y de responsabilidad que pudieran corresponder.

2. Para la supresión o modificación de la causa de separación a que se refiere el apartado anterior, será necesario el consentimiento de todos los socios, salvo que se reconozca el derecho a separarse de la sociedad al socio que no hubiera votado a favor de tal acuerdo.

3. El plazo para el ejercicio del derecho de separación será de un mes a contar desde la fecha en que se hubiera celebrado la junta general ordinaria de socios. 
4. Cuando la sociedad estuviere obligada a formular cuentas consolidadas, deberá reconocerse el mismo derecho de separación al socio de la dominante, aunque no se diere el requisito establecido en el párrafo primero de este artículo, si la junta general de la citada sociedad no acordara la distribución como dividendo de al menos el veinticinco por ciento de los resultados positivos consolidados atribuidos a la sociedad dominante del ejercicio anterior, siempre que sean legalmente distribuibles $y$, además, se hubieran obtenido resultados positivos consolidados atribuidos a la sociedad dominante durante los tres ejercicios anteriores.

5. Lo dispuesto en este artículo no será de aplicación en los siguientes supuestos:

a) Cuando se trate de sociedades cotizadas o sociedades cuyas acciones estén admitidas a negociación en un sistema multilateral de negociación.

b) Cuando la sociedad se encuentre en concurso.

c) Cuando, al amparo de la legislación concursal, la sociedad haya puesto en conocimiento del juzgado competente para la declaración de su concurso la iniciación de negociaciones para alcanzar un acuerdo de refinanciación o para obtener adhesiones a una propuesta anticipada de convenio, o cuando se hay a comunicado a dicho juzgado la apertura de negociaciones para alcanzar un acuerdo extrajudicial de pagos.

d) Cuando la sociedad haya alcanzado un acuerdo de refinanciación que satisfaga las condiciones de irrescindibilidad fijadas en la legislación concursal.

e) Cuando se trate de Sociedades Anónimas Deportivas.

Con esta modificación, se reducía cuantitativamente lo que dio en llamarse el "dividendo mínimo" -se pasa del tercio de los beneficios al 25\%-, se agravaban los requisitos para el ejercicio del derecho de separación que serán desarrollados en el apartado siguiente y se aumentan los supuestos en los que no sería de aplicación lo previsto en este precepto.

\subsection{Requisitos para su ejercicio}

Para el ejercicio del derecho de separación previsto en el artículo 348 bis, habrán de concurrir las siguientes condiciones:

a) Legitimación pasiva: el primer requisito al que se alude en el precepto extiende su aplicación, con las excepciones que luego se dirán, a todas las sociedades mercantiles con independencia de la fecha de constitución o la de la entrada en vigor del propio artículo 348 bis. Asimismo, y por lo que respecta a 
los ejercicios sociales computables ${ }^{19}$, se debe interpretar que el acuerdo de aplicación del resultado que motiva -en caso de no distribución de dividendosel derecho de separación debe producirse, al menos, en el sexto año desde la fundación de la sociedad, respecto de los resultados del año anterior.

Hacer notar que, en congruencia con la voluntad teleológica del legislador a la hora de introducir este precepto como herramienta antiabusiva frente a la mayoría, con la reforma de 2018, se introduce la necesidad de que no se hubieran repartido dividendos en los cinco ejercicios anteriores equivalentes al $25 \%$ de los beneficios repartibles generados durante ese periodo.

b) Legitimación activa: el derecho de separación puede ser ejercido por aquellos socios que hubieran hecho constar en acta su protesta por la insuficiencia del reparto de dividendos ${ }^{20}$.

Algunos autores debaten la posibilidad de otorgar el derecho de separación a aquellos socios que se hubieran mantenido ausentes, se hubieran abstenido o hubieran votado en blanco, o a los accionistas a los que se les hubiera privado de su derecho de voto por mantenerse en mora por desembolsos pendientes (ex artículo 83.1 de la Ley de Sociedades de Capital). Sin embargo, el elemento de voluntariedad en esos supuestos -no así de tratarse de socios o accionistas sin voto ex artículo 98 y ss. de la Ley de Sociedades de Capital- debe hacernos reflexionar si esos socios son merecedores de la protección frente al supuesto abuso de la mayoría cuando, en determinados casos, puede encontrarse ausente, incluso, la lealtad para con la sociedad y sus socios. De hecho, existen resoluciones judiciales que excluyen estos casos; ejemplo de ello son las Sentencias de 25 de septiembre de 2013 y de 1 de marzo de 2018 del Juzgado de lo Mercantil $\mathrm{n}^{\circ} 9$ de Barcelona.

c) Beneficios legalmente repartibles: procedería la separación en caso de que no se repartiera, al menos, el veinticinco por ciento de los beneficios legalmente distribuibles ${ }^{21}$, siempre y cuando se hubieran obtenido beneficios en los tres ejercicios sociales precedentes a aquél cuya aplicación de resultado se esté

${ }^{19}$ No parece ser muy acertado computar el plazo en ejercicios, teniendo en cuenta que el primer ejercicio, en función de la fecha de constitución, no tendrá la misma duración que los sucesivos y que, los primeros tiempos de andadura de la sociedad suelen ser de pérdidas, de dificultades financieras y de especial implicación económica de los socios.

${ }^{20}$ Antes de la reforma de 2018 se exigía que se hubiera votado a favor de la distribución de dividendos, lo que se antojaba ciertamente difícil cuando, quien propone la aplicación del resultado es el órgano de administración, generalmente en manos de los socios mayoritarios, interesados, a menudo, de mantener las ganancias sociales en la compañía.

${ }^{21}$ La norma no especifica si el pago de los dividendos ha de hacerse mediante pagos en metálico o en especie. 
sometiendo a aprobación, todo ello salvo que en los cinco ejercicios anteriores a éste, como ya se ha dicho, se hubiera repartido, al menos, el veinticinco por ciento de los beneficios registrados en este lustro.

Nótese respecto de la literalidad previa a la reforma de 2018 que ya no quedan excluidos aquellos ingresos extraordinarios o atípicos ajenos a su actividad ordinaria fruto del desarrollo de su objeto social ${ }^{22}$; por tanto, no se descontaría cantidad alguna por ningún concepto para hallar el veinticinco por ciento mínimo de dividendos.

Asimismo, debe tenerse en cuenta que, en caso de que en la misma Junta se sometan a aprobación las Cuentas Anuales de varios ejercicios, únicamente se tendrá en consideración a efectos del artículo 348 bis el último de ellos; la norma actualmente vigente sólo se refiere al "ejercicio anterior" en sentido estricto $^{23}$.

d) Plazo de ejercicio: el plazo de ejercicio del derecho de separación es de un mes desde la celebración de la Junta General. Toda vez que no se encuentra previsto un límite mínimo para su ejercicio, puede iniciarse en la propia Junta General realizando las manifestaciones correspondientes al efecto.

e) Forma: el modo de ejercer -o de iniciar- el derecho de separación no se encuentra expresamente determinado por la $\mathrm{Ley}^{24}$, siendo lo óptimo la utilización de una vía que asegure fehacientemente tanto su envío como su recepción.

En todo caso, dada la redacción actual del artículo 348 bis de la Ley de Sociedades de Capital, y una vez ejercitado el derecho de separación, habría que estar vigilante a que el socio no hubiera actuado de mala fe, empleando abuso del derecho y vulnerando su deber de lealtad.

Finalmente, y como excepción a la aplicación de este artículo, su apartado 5 prevé la no aplicación del mismo, además de al supuesto previsto en la redacción de la Ley 25/2011 -sociedades cotizadas-, a aquellas sociedades cuyas acciones

${ }^{22}$ Este extremo invalidaría, a efectos interpretativos, la propia justificación de la enmienda que introdujo en su día el artículo 348.bis pues se recogían como ejemplo las plusvalías obtenidas por la enajenación de un bien que formaba parte del inmovilizado fijo.

${ }^{23}$ Sentencia 380/2018 de la Audiencia Provincial de Zaragoza, Sección $5^{\mathrm{a}}$, de 17 mayo de 2018, Rec. 486/2018.

${ }^{24}$ La Sentencia 952/2019 de la Audiencia Provincial de Valencia, Sección 9a de 9 de julio de 2019, sostiene que este derecho de separación especial no se encuentra vinculado por el artículo 348 de la Ley de Sociedades de Capital y, en consecuencia, no se encontraría exigida la comunicación escrita ni el plazo de un mes comenzaría desde la comunicación o publicación del acuerdo y sería admisible la comunicación in voce en la propia Junta. 
estén admitidas a negociación en un sistema multilateral de negociación, las que se encuentren en concurso de acreedores, hubieran presentado "preconcurso" al amparo de lo previsto en el artículo 5 bis de la Ley 22/2003, de 9 de julio, Concursal o hubieran alcanzado un acuerdo de refinanciación conforme a la legislación concursal, así como a las sociedades anónimas deportivas.

\subsection{Procedimiento de separación}

Como se ha indicado en el apartado anterior, el procedimiento de separación por no reparto de dividendos comienza con una comunicación (preferiblemente escrita y fehaciente) del socio dirigida a la sociedad en plazo de un mes desde la adopción del acuerdo de aplicación de resultado, no existiendo impedimento legal alguno para su comunicación en la propia Junta Genera ${ }^{25}$. Se antoja esencial por razones obvias el que la comunicación escrita deje constancia de su entrega o, en su caso, se haga constar en el acta correspondiente, teniendo en cuenta que es en el momento de la recepción, sin necesidad de aceptación, cuando comienzan a desplegarse los efectos del ejercicio del derecho.

Remitida la comunicación, procede la valoración de las participaciones o las acciones del socio que se separa para lo que, en defecto de pacto entre éste y la sociedad, se designará al efecto un experto independiente por el Registro Mercantil del domicilio de la compañía.

El experto independiente, cuya retribución correrá a cargo de la sociedad, deberá emitir su informe en el plazo de dos meses, para lo que tendrá acceso a cuanta información de la compañía considere útil.

Tras la notificación del informe del experto -que se realizará por conducto notarial- a la sociedad y al socio interesado, y cuya copia se depositará en el Registro, comienza un plazo de dos meses en los que el socio podrá obtener en el domicilio social el valor razonable de su participación. Transcurridos los dos meses sin que el socio hubiera acudido, los administradores deben consignar la cantidad en una entidad que radique en el domicilio social a favor del socio interesado.

En caso de que fuera preceptivo el derecho de oposición de los acreedores, el reembolso sólo podrá producirse una vez transcurridos tres meses desde la notificación personal a los acreedores o la publicación en el BORME y en

\footnotetext{
${ }^{25}$ Sentencia 952/2019 de la Audiencia Provincial de Valencia, Sección $9^{\text {a }}$, de 9 de julio de 2019, Rec. 2149/2018.
} 
uno de los diarios de mayor circulación de la localidad del domicilio social y siempre que, naturalmente, ningún acreedor se hubiera opuesto. Sin perjuicio de esto, el que ningún acreedor ejerza su derecho de oposición no excluye de responsabilidad por las deudas sociales generadas con anterioridad a la fecha en la que los acreedores se hubieran podido oponer, respondiendo el socio separado, como límite máximo, del importe percibido, prescribiendo a los cinco años.

Desde la óptica de la sociedad, la separación del socio se puede ejecutar mediante la reducción de capital por amortización de las acciones o las participaciones sociales o su adquisición para su autocartera, lo cual deberá ser autorizado por la Junta General. En el primero de los casos, los administradores elevarán a público, sin necesidad de intervención de la Junta, la reducción de capital precisando las acciones o participaciones amortizadas, el socio separado, la fecha de reembolso o de la consignación y la cifra resultante de la reducción de capital.

$\mathrm{Y}$ en el segundo de los supuestos, adquisición de las participaciones o acciones para autocartera, los administradores, igualmente sin necesidad de acuerdo de Junta General ni del concurso del socio separado, elevarán a público la adquisición indicando las participaciones o acciones adquiridas, la identidad del socio separado, la causa de separación y la fecha de pago o consignación.

La sociedad habrá de estar vigilante de no incurrir en causa de disolución por situarse por debajo del mínimo legal, en caso de reducción de capital, ni de superar el umbral temporal máximo de tenencia de autocartera.

\subsection{Pérdida de la condición de socio}

Desde la aprobación de la primera de las redacciones del artículo 348 bis por parte de la Ley 11/2015, se suscitó el debate de los efectos del derecho de separación respecto de la cualidad de socio; esto es: desde cuándo se produce la salida de la sociedad del socio que ha ejercido su derecho de separación. Este extremo resulta esencial porque determina la legitimidad para el ejercicio de los derechos propios del socio o, en su caso, incluso la calificación concursal del crédito que eventualmente se pueda generar.

Por su parte, el legislador de 2018 no resolvió el problema y, en la actualidad, tanto la doctrina científica como la judicial se agrupan en defensa de tres tesis: la que sostiene que se pierde la condición de socio en el momento de la comunicación inicial del ejercicio del derecho de separación; la que entiende que esa pérdida tendrá lugar cuando la sociedad se dé por notificada; y la que 
sostiene que únicamente tendrá lugar su salida del capital cuando se abone al socio saliente su cuota de liquidación o cuando, al menos, ésta sea puesta a su disposición.

Por su parte, las Sentencias 12/2018 ${ }^{26}$ y 113/2018 de la Audiencia Provincial de La Coruña, Sección 4a de 15 de enero de 2018 (Rec. 640/2017) y 28 de marzo de 2018 (Rec. 637/2017), respectivamente, invocando la Sentencia 32/2006 del Tribunal Supremo, Sala 1a, de 23 de enero de 2006 (Rec. 1949/2003), sostienen que la consideración de socio decae desde el momento en el que se comunica a la sociedad el ejercicio del derecho de separación por entender que no es un derecho in fieri que precise de la concurrencia de la sociedad o sus administradores para su eficacia y despliegue de sus efectos, pues lo contrario generaría un derecho ilusorio por parte del socio, en una suerte de dependencia de la mera potestad de la compañía (...). Los actos a realizar por la sociedad son actos debidos, y no condiciones potestativas.

Sin embargo, contrariamente a esta interpretación hallamos la fundamentación de las Sentencias de la Sección $3^{\mathrm{a}}$ de la Audiencia Provincial de Castellón de 26 de enero de 2017 y 239/2011 de 8 de julio de 2011 (Rec. 150/2011) y 195/2015 de la Sección 5 a de la Audiencia Provincial de Cádiz de 16 de abril de 2015 (Rec. 613/2014). En este sentido, esta última resolución -la Sentencia 195/2015 de la Audiencia de Cádiz- afirma que "si bien la declaración de separación no tiene como consecuencia la cesación automática e inmediata de la condición de socio, es indudable que desde que aquélla tiene lugar el vínculo social queda afectado entrando en una fase de decadencia (BRENES CORTÉS, J., “¿En qué momento se consolida el derecho de separación del socio en una SRL?", en Actualidad Jurídica Aranzadi, núm. 715/2006). Pero no se difumina, ni deja de existir". Y ello hace que continúe en posesión de todos los derechos inherentes a su condición de socio: la separación de la sociedad genera el derecho del socio al reembolso del valor de sus participaciones y, mientras tanto, sigue siendo socio a todos los efectos. Admitir que, pese a seguir siendo socio -lo que es innegable-, no puede intervenir en la marcha de la mercantil $y$, por ello, no ostenta legitimación para impugnar los acuerdos supondría su relegación a una especie de limbo económico y jurídico de incierto final. El ejercicio del derecho de separación no implica por sí y antes del reembolso del valor de las participaciones la desvinculación del socio que se separa que, además, sigue teniendo un interés objetivo en la marcha de la sociedad, en la medida en que del grado de solvencia y liquidez de la misma puede depender la efectiva satisfacción de su derecho a la percepción del valor de las participaciones.

\footnotetext{
${ }^{26}$ No es firme; pendiente de resolución del recurso de casación interpuesto.
} 
Asimismo, debemos tener presente el Anteproyecto de Código Mercantil como criterio interpretativo de primer orden pues en el apartado 1 de su artículo 271-23 que viene al auxilio de esta tesis previendo:

El socio quedará separado o excluido de la sociedad a partir del momento del reembolso o de la consignación del valor de la parte social de la que fuera titular.

Doctrinalmente, se ha indicado por la profesora Josefa Brenes Cortés que la declaración de separación no tiene como consecuencia la cesación automática e inmediata de la condición de socio, pero desde que aquella tiene lugar el vínculo social queda afectado entrado en una fase de decadencia. Esta interpretación presenta, a su vez, como ventaja indudable, la posibilidad de que el socio que haya manifestado su voluntad de separarse pueda revocar su declaración y evitar el procedimiento de reembolso; además, y aun cuando el vínculo social del socio que emite la declaración de separación resulte debilitado, permite imputarle los resultados producidos en las operaciones sociales durante el periodo que media entre dicha declaración y la extinción definitiva de su condición de socio ${ }^{27}$.

En definitiva, el debate sobre el momento de pérdida del status socii continúa abierto y tiene su reflejo más importante en la calificación concursal del derecho de crédito que tendría el socio saliente en el caso de que la sociedad entrara en concurso de acreedores antes de que se hubiera liquidado.

\subsection{Calificación concursal del crédito derivado del ejercicio del derecho de separación}

Pues bien, tal y como acabamos de analizar, uno de los campos en los que más puede afectar cuándo se entiende roto el vínculo societario socio-sociedad es en el ámbito concursal cuando la compañía entra en concurso después del ejercicio del derecho de separación, pero antes del pago del valor de su participación.

Pues bien, las citadas Sentencias 12/2018 y 113/2018 de la Audiencia Provincial de La Coruña resuelven en apelación sendos incidentes concursales en los que se termina calificando el principal de estos créditos como ordinarios y sus intereses, como crédito subordinado-. Y lo hacen empleando tres argumentos:

27 Artículo titulado "Clasificación concursal del crédito de reembolso del socio que se separa ex artículo 348 bis LSC. A propósito de la SAP Coruña 12/2018, de 15 de enero 2018”, en Revista de Derecho Concursal y Paraconcursal, no 29, Sección Comentarios y Reseñas de Jurisprudencia / Comentarios de Jurisprudencia, Segundo semestre de 2018, Editorial Wolters Kluwer. 
- Que el socio saliente -como se ha indicado en el apartado precedente- ya no tiene vínculo societario con la sociedad concursada y, en consecuencia, ya no sería persona especialmente relacionada" (art. $92.5^{\circ} \mathrm{LC}^{28}$ ); esto es: la separación o exclusión trae consigo la pérdida de la condición jurídica de socio de quienes han tomado libremente la decisión de abandonarla, en los casos legal o estatutariamente previstos, o han sido apartados de la sociedad en contra de su voluntad. Lógica consecuencia de tales actos jurídicos es la obligación social de restituir al socio el valor de sus acciones;

- Que dicho crédito no tendría la misma naturaleza que el que podría tener la cuota de liquidación de un socio en un escenario de disolución y liquidación; esto es: en modo alguno, la ley condiciona la percepción del reembolso, en el caso del ejercicio del derecho de separación, a la previa liquidación de los créditos de los acreedores sociales por deudas anteriores al ejercicio de tal derecho, sino que ofrece otros mecanismos de protección, por lo que la equiparación que efectúa la sentencia apelada no nos vale a los efectos de clasificación del crédito litigioso; y

- Que tampoco podría asimilársele a un crédito con análoga finalidad a un préstamo; esto es: no podemos considerar, por consiguiente, que el crédito de la actora, (...) sea equivalente a un préstamo o acto análogo, pues el mismo no deriva de una entrega a la sociedad de ninguna cosa fungible o dinero para usar de ella y devolver otro tanto de la misma especie y calidad, en los términos del art. 1740 del CC, sino del ejercicio de un derecho societario a la separación por falta de reparto de beneficios y frustración de la finalidad de toda sociedad mercantil, que es cuestión asaz diferente. Pese a que la redacción del art. 92.5 LC podría ser más clara, del mismo deriva que la subordinación se produce sobre los préstamos o actos de análoga finalidad de los que son acreedores personas especialmente relacionadas con la persona jurídica concursada, quedando, por consiguiente, excluidas otras posiciones crediticias.

Si bien la Audiencia Provincial de La Coruña fundamenta con rigor y contundencia su posición, ésta no resulta indiscutida y será necesaria una reforma legislativa o un pronunciamiento unificador por parte del Tribunal Supremo que otorgue mayor seguridad a todas las partes afectadas en el marco concursal.

${ }^{28}$ Art. 281.1.5 ${ }^{\circ}$ del Real Decreto Legislativo 1/2020, de 5 de mayo, por el que se aprueba el Texto Refundido de la Ley Concursal, que entrará en vigor el próximo 1 de septiembre de 2020. 


\subsection{Derecho de arrepentimiento de la sociedad}

Con "derecho de arrepentimiento" de la sociedad se refiere la doctrina y la jurisprudencia a la táctica de que la Junta General apruebe inicialmente la aplicación del resultado a fines distintos a los del reparto de dividendos y, ante la eventualidad de que algún socio pudiera ejercitar el derecho de separación, se vuelva a someter a votación de la Junta el destino de los beneficios y, ahora sí, se apruebe su reparto como dividendos.

Esta estrategia -de una discutible buena fe- ha venido siendo consentida por la jurisprudencia con el único límite de aquellos socios que, para el momento en que se hubiera procedido a una "reconsideración" del acuerdo de aplicación del resultado por parte de la Junta General, ya hubieran ejercido su derecho de separación. En este sentido, la Sentencia 32/2006 del Tribunal Supremo, Sala 1 ${ }^{\text {a }}$, de 23 de enero de 2006 (Rec. 1949/2003) dejó sentado: la sociedad carece de ese derecho, que la Sentencia presenta como innegable, a dejar sin efecto el acuerdo de modificación en perjuicio de quien, confiado en tal acuerdo, ha ejercitado ya el derecho que la ley le confiere. Es "innegable" únicamente que la sociedad podrá rectificar, desistir, arrepentirse o renunciar, pero en tal caso nunca en perjuicio de quien ya ha ejercitado el derecho, salvo que cuente con su conformidad. Se deduce esta regla del artículo 6.2 del Código civil, ya que el desistimiento, como acto abdicativo unilateral no puede perjudicar a quien ha adquirido ya un derecho por razón de un acto anterior del renunciante.

Esta fundamentación es invocada por resoluciones posteriores como la Sentencia del Tribunal Supremo de 18 de octubre de 2012, la Resolución de la Dirección General de los Registros y del Notariado de 20 de septiembre de 2017 o la Sentencia 952/2019 de la Audiencia Provincial de Valencia, Sección $9^{\text {a }}$, de 9 de julio de 2019 (Rec. 2149/2018) que considera que ni siquiera cabe alegar el riesgo de insolvencia de la sociedad [que] debió ser valorado ex ante.

\subsection{Función del Registrador en la designación del experto independiente}

Como se ha dicho, una vez ejercido el derecho de separación y en caso de desacuerdo respecto del contravalor de la participación del socio saliente, procede el nombramiento de un experto independiente por parte del Registrador Mercantil del domicilio social. Pues bien, no es pacífico el alcance de la función del Registrador en el expediente registral de designación del experto y su posible conflicto competencial con el orden jurisdiccional a la hora de determinar si el derecho de separación se ha ejercitado o no correctamente y en qué términos se puede producir una eventual oposición de la sociedad a su nombramiento. 
Así, nuestra doctrina judicial ha venido sosteniendo que, con la solicitud de nombramiento de un experto independiente, el Registrador únicamente debe llevar a cabo un examen puramente formal al amparo de lo previsto en el artículo 354.2 de la Ley de Sociedades de Capital. En este sentido, la Audiencia Provincial de Barcelona, Sección 15a , en su Sentencia 1745/2019 de 7 de octubre de 2019 (Rec. 1051/2019), afirma: no consiste en determinar si el derecho de separación se ha ejercitado o no correctamente por los socios. La función del registrador no puede alcanzar al fondo, esto es, a si se ha ejercitado o no correctamente por los socios el derecho de separación del art. 348-bis LSC sino que se ha de limitar a si concurren los presupuestos para que proceda el nombramiento de experto independiente, lo que no es exactamente lo mismo. Es cierto que constatar si concurren los presupuestos para que proceda el nombramiento de experto puede exigir que el registrador analice si existía realmente el derecho de separación invocado y si aparece formalmente ejercitado de forma adecuada, si bien se trata de un examen puramente formal.

Asimismo, por lo que respecta a la eventual oposición de la sociedad al nombramiento del experto, ésta no puede ir más allá de los aspectos puramente formales que pueden justificar el nombramiento, sin extenderse a las cuestiones sustantivas.

En suma, el Registrador Mercantil debe dilucidar si procede nombrar experto, no sobre si existe o no un derecho de separación correctamente ejercitado; esta misma tesis es sostenida, entre otras, por la Sentencia de la Audiencia Provincial de Murcia de 28 de marzo de 2018 (ROJ:SAP MU 742/2018), y por la Sentencia de la Audiencia Provincial de Madrid, Sección 28. ${ }^{\text {a }}$, de 30 de noviembre de $2018\left(\right.$ Rec. 612/2017) ${ }^{29}$.

\subsection{Coexistencia con los principios constitucionales}

Desde la aparición del artículo 348 bis de la Ley de Sociedades de Capital, se ha suscitado el debate doctrinal de si este precepto no colisionaría con el principio de libertad de empresa consagrado en el artículo 38 de la Constitución $^{30}$ al entender limitada la facultad directiva de decidir libremente sobre la aplicación del resultado.

${ }^{29}$ Existen igualmente resoluciones en este sentido en Primera Instancia como la Sentencia del Juzgado de lo Mercantil $\mathrm{n}^{\circ} 1$ de Sevilla de 26 de septiembre de 2017 o la del Juzgado de lo Mercantil no 3 de Vigo 15 de noviembre de 2018.

30 Se reconoce la libertad de empresa en el marco de la economía de mercado. Los poderes públicos garantizan y protegen su ejercicio y la defensa de la productividad, de acuerdo con las exigencias de la economía general y, en su caso, de la planificación. 
Debido al grado constitucional de la libertad de empresa, para la intervención de los poderes públicos en el ámbito mercantil, es necesaria la existencia de intereses generales superiores. Sin embargo, la introducción en la Ley de Sociedades de Capital de este precepto -ciertamente mejorable- se halla perfectamente justificada: la protección del socio minoritario, hasta entonces desamparado, el frecuente abuso de derecho por parte del socio mayoritario, que se aseguraba el retorno de su inversión por otros cauces no alcanzables por los minoritarios, y la positivización del derecho al reparto de dividendos en congruencia con los artículos 116 del Código de Comercio y 93 de la Ley de Sociedades de Capital.

Igualmente, el artículo 348 bis tampoco deja sin contenido las competencias del administrador a proponer la aplicación del resultado, ni de la Junta General de decidir sobre él toda vez que, como se ha visto en apartados anteriores de este trabajo, la obligatoriedad del reparto incumbe únicamente a un $25 \%$ de los beneficios repartibles legalmente. Es decir, los juegos de las mayorías aún podrán decidir, teniendo en cuenta la situación económico-financiera de la compañía y con la máxima libertad, sobre el $75 \%$ del resultado. Un cercenamiento decisorio tan mínimo no parece tener la entidad suficiente como para tachar el precepto de contrario al artículo 38 de la Constitución, cuyo derecho constitucional puede encontrarse justificadamente sometido a limitaciones máxime cuando ése se refiere únicamente a la libertad de acceso al mercado, libertad de ejercicio y libertad de cesación en el mercado ${ }^{31}$.

Finalmente, hay autores que consideran que el artículo 348 bis podría entrar también en colisión con los principios igualmente constitucionales de seguridad jurídica, proporcionalidad e interdicción de la arbitrariedad de los poderes públicos recogidos en el artículo 9.3 de la Constitución ${ }^{32}$. No comparto esa tesis: todos los socios, tanto mayoritarios como minoritarios, cuando deciden formar parte de una sociedad mercantil, son conscientes de su propio ánimo de lucro y conocedores del resto, así como del derecho económico -aunque abstractoal dividendo, por lo que no podría alegarse inestabilidad ni perjuicio cuando de lo que se está hablando es del abuso de derecho.

Naturalmente, tampoco nos encontraríamos ante una arbitrariedad de los poderes públicos cuando se trata de proteger a los socios minoritarios del abuso de derecho ejecutado por los mayoritarios -si tomamos como referencia la justificación de la enmienda parlamentaria- o el desarrollo expreso y concreto a

\footnotetext{
${ }^{31}$ Sentencias del Tribunal Constitucional 112/2016, 11/1983 y 225/1993.

${ }^{32}$ La Constitución garantiza el principio de legalidad, la jerarquía normativa, la publicidad de las normas, la irretroactividad de las disposiciones sancionadoras no favorables o restrictivas de derechos individuales, la seguridad jurídica, la responsabilidad y la interdicción de la arbitrariedad de los poderes públicos.
} 
aquel ánimo de lucro que movió a los socios a constituir o entrar en una sociedad mercantil -si tomamos como referencia el tenor literal del precepto-.

\section{REGULACIÓN PREVISTA EN EL NON NATO CÓDIGO MER- CANTIL}

Uno de los proyectos legislativos más ambiciosos de los últimos años, esperado ya con impaciencia por parte de los operadores jurídicos y económicos y cuyos retrasos sólo se pueden justificar por la magna obra compilatoria y legislativa, es el Código Mercantil que reúna en un único cuerpo legal todo el Derecho Mercantil y de Sociedades de España, introduciendo importantes novedades.

Pues bien, este Código fue aprobado por el Consejo de Ministros el 30 de mayo de 2014 y remitido a las Cortes como Anteproyecto de Ley con el objeto de comenzar su trámite parlamentario -en el que se encuentra estancado desde entonces-. En él, como una de las novedades más destacadas del proyectado Código, se incluye, en su Libro II, un Título VII, De la separación y de la exclusión de socios y de la disolución, liquidación y extinción de las sociedades mercantiles, en el que se prevé la separación por falta de reparto de dividendos por entender los autores de la propuesta oportuno mantener el derecho de separación que trae causa en la falta de reparto de beneficios en las sociedades de capital, si bien se han restringido las circunstancias de cuantía y tiempo que habilitan el derecho con el fin de establecer un mayor equilibrio entre el legítimo interés de la sociedad a aplicar razonablemente el resultado y el del socio a hacer efectiva su participación en el beneficio repartible, evitando a la vez los eventuales abusos de mayoría que se concretan en reiteradas estrategias de neutralización del derecho económico de los socios en minoría ${ }^{33}$.

Así, en el artículo 271-1, se prevé la exclusión de un socio en cualquier momento mediando justa causa para, en los artículos siguientes, con una técnica legislativa discutible ${ }^{34}$, regular los supuestos concretos en los que el socio de una mercantil tendrá derecho de separación.

\footnotetext{
${ }^{33}$ Exposición de Motivos III-78 del Anteproyecto de Ley de Código Mercantil.

${ }^{34}$ Afirma al respecto en el Dictamen 837/2014 del Consejo de Estado aprobado el 29 de enero de 2015 que existen importantes dificultades interpretativas y de comprensión sistemática, entiende este Consejo que puede en ocasiones inducir a error, pues se advierte la existencia de solapamientos en el contenido de algunos artículos, al tiempo que, en otros casos, se aprecia una discordancia entre la rúbrica del artículo y su contenido o que el Consejo de Estado estima que el nuevo Código ganaría en claridad si reordenase las causas de separación.
} 
Por lo que a este trabajo respecta, hay que acudir al artículo 271-6, que introduce novedades respecto al texto del artículo 348 bis introducido por la Ley 25/2011 en la Ley de Sociedades de Capital; el 271-6 dispone:

1. A partir del quinto ejercicio desde la inscripción de la sociedad en el Registro Mercantil, el socio que hubiera votado en contra de la propuesta de aplicación del resultado, tendrá derecho de separación en el caso de que la junta general no acordara la distribución como dividendo de, al menos, una cuarta parte de los beneficios propios de la explotación del objeto social, que sean legalmente repartibles, siempre que se hayan obtenido dichos beneficios durante los dos ejercicios anteriores.

2. El derecho de separación no podrá ejercitarse si existiese un acuerdo de refinanciación homologado por el juez, o si la sociedad se encuentra en concurso.

3. Lo dispuesto en este artículo no será de aplicación a las sociedades cotizadas.

Así, del estudio comparado de las dos normas -el artículo 348 bis y el 271-6- se advierten importantes similitudes, principalmente tras la reforma de 2018 que ha bebido del Anteproyecto de Código Mercantil para mejorar su redacción y superar determinadas críticas que se le venían haciendo:

a) Se pasa a hablar de voto en contra de la propuesta de aplicación del resultado y no de hacer constar en el acta su protesta por la insuficiencia de los dividendos reconocidos, como dice el texto de 2018, o a favor de la distribución de los beneficios, como dice el de 2011; muchos autores se venían preguntando cómo el socio iba a votar a favor de la distribución de dividendos cuando el órgano de administración de la compañía (ex art. 253.1 LSC) proponga solamente la dotación de reservas voluntarias.

b) Tanto en el Código Mercantil como en la reforma de 2018, se reduce el importe a distribuir como dividendos a una cuarta parte de los beneficios obtenidos, frente al tercio previsto en el artículo 348 bis LSC de la Ley $25 / 2011$.

c) Para el ejercicio del derecho de separación, el Anteproyecto de Código exige que la compañía hubiera tenido beneficios en los dos ejercicios inmediatamente anteriores. La redacción vigente lo eleva a tres ejercicios e introduce el elemento moderador de que, en los cinco ejercicios anteriores se hubiera repartido el $25 \%$ del beneficio de dicho periodo. El texto de 2011 no preveía mecanismo equilibrador al respecto. 
d) Finalmente, se incluye en el artículo 271-6.2 dos excepciones al ejercicio del derecho por el socio: que exista un acuerdo de refinanciación homologado judicialmente o que la sociedad se encuentre en concurso. La reforma de la Ley 11/2018 prevé, además de a las sociedades cotizadas, a las admitidas a negociación en los mercados multilaterales, las concursadas o al amparo del artículo 5 bis de la Ley Concursal, las que hubieran alcanzado un acuerdo de refinanciación y las sociedades deportiva; por su parte, el legislador de 2011 únicamente excepcionaba a las sociedades cotizadas de la aplicación de este precepto.

\section{ABUSOS Y DIFICULTAD PARA HALLAR EL PUNTO DE EQUILIBRIO}

\subsection{Abusos de la minoría}

Como se ha indicado, la redacción neutra del artículo 348 bis de la Ley de Sociedades no permite circunscribir el ejercicio del derecho de separación a casos de no distribución de dividendos por abuso de la mayoría, permitiendo, por el contrario, exigir el reparto en todos los supuestos.

Por ello, para ser fieles a la justificación de la enmienda parlamentaria que incluyó este precepto, el derecho de separación tan sólo podría ser ejercido por los minoritarios que fueran víctimas de abuso de derecho pues, de lo contrario, podría el sector minoritario del capital obligar a la compañía a repartir dividendos -so pena de separarse y, en consecuencia, de costarle más caro a la sociedad- en todos los ejercicios con independencia de los intereses social y de terceros que pueden existir en ese ejercicio o en los siguientes. En ese caso, nos encontraríamos ante el abuso de la minoría que impone una carga desproporcionada a aquellos socios que, conscientes del resto de intereses en liza, adopten el acuerdo de dotar reservas voluntarias de forma leal y conforme a Derecho.

En este sentido, como el resto de la doctrina ${ }^{35}$, la profesora Campins afirma: no puede desconocerse tampoco que el reconocimiento del derecho de separación en los términos literales que prevé el precepto puede acabar

${ }^{35}$ Greenmail y amortización no paritaria de acciones y de participaciones. Un análisis crítico del estado de la cuestión en nuestra jurisprudencia, Fernández del Pozo. Revista de Sociedades, $n^{\circ}$ 21, 2003; PAZ-ARES, C., "Aproximación al estudio de los squeeze-outs en el derecho español", en Revista de Derecho Bancario y Bursátil, no 91 (2003); GONZÁLEZ CASTILLA, "Reconocimiento del derecho de separación en caso de falta de distribución de dividendos (introducción del nuevo art. 348 bis LSC)", en GONZÁLEZ CASTILLA, RODRÍGUEZ ARTIGAS, y FARRANDO MIGUEL, Las reformas de la Ley de Sociedades de Capital", Ed. Aranzadi, 2012, p. 266; y BRENE CORTÉS, "Derecho de la minoría al dividendo: el controvertido art. 348 bis LSC", en Revista Aranzadi Doctrinal, nº 8 (2012) 142. 
convirtiendo a los socios en meros acreedores de un derecho de crédito frente a la sociedad, con el resultado práctico de acabar transformando el abuso de la mayoría en abuso de la minoría en lo que a politica de dividendos se refiere ${ }^{36}$.

\subsection{Equilibrio entre los distintos intereses}

Uno de los elementos más controvertidos del artículo 348 bis de la Ley de Sociedades de Capital es el hecho de que ampare únicamente -y supuestamentea los socios minoritarios, sin observar los intereses de la propia sociedad y de terceros.

Por lo que respecta a los intereses sociales, muchos autores destacan que el riesgo al abuso de la minoría pueda poner en peligro el interés social que aconsejaría el mantenimiento de todos los recursos de la compañía en aras a su equilibrio económico-financiero o a su endeudamiento a largo plazo, lo que no resultaría conveniente en momentos de crisis económica.

Tanto la exigencia de reparto de dividendos, como el pago de la cuota al socio, en caso de ejercicio del derecho de separación, podría igualmente impedir el acceso a financiación externa, máxime en contextos de crisis económica que harían recomendable su reinversión y la recapitalización de los recursos.

Asimismo, es conveniente tener presente que en los contratos financieros de la mayoría de nuestras sociedades se incluyen cláusulas que limitan la autonomía de sus órganos a la hora de decidir el destino de los beneficios (control de gastos); estas cláusulas determinan, a menudo, la composición de los fondos propios o de los ratios correspondientes a reservas o deuda externa. Finalmente, la salida de un socio del capital de una sociedad, tras el ejercicio del derecho de separación, podría desencadenar cambios de control en ella, generalmente previstos en los contratos financieros como ownership clause.

\section{BIBLIOGRAFÍA Y FUENTES}

- ALFARO ÁGUILA-REAL, J., Derecho de separación en el saco de sequía de dividendos II. Entrada en el blog http://derechomercantilespaña.bolgspot.com.

- ÁlVAREZ ROYO-VILANOVA, S., y FERNÁNDEZ DEL POZO, L., "Propuesta de redacción alternativa del artículo 348 bis LSC", en Revista La Ley Mercantil, 33 (2017).

\footnotetext{
36 "Derecho de separación por no reparto de dividendos: ¿es un derecho dispoible por los socios?", en Diario La Ley, 7824, 23 de marzo de 2012.
} 
- Boletín Oficial de las Cortes Generales. Congreso de los Diputados. Serie A, 25 de febrero de 2011; $\mathrm{N}^{\circ}$ A-111-11, de 30 de mayo de 2011; Serie D, 6 de marzo de 2012, núm. 49.

- BRENES CORTÉS, J., "Clasificación concursal del crédito de reembolso del socio que se separa ex artículo 348 bis LSC. A propósito de la SAP Coruña 12/2018, de 15 de enero 2018", en Revista de Derecho Concursal y Paraconcursal, 29 (2018).

- BRENES CORTÉS, J., "Derecho de la minoría al dividendo: el controvertido art. 348 bis LSC", en Revista Aranzadi Doctrinal, 8 (2012).

- BRENES CORTÉS, J., "El derecho de separación por falta de distribución de dividendos en el seno de los grupos de sociedades", en Revista Lex Mercatoria, 11 (2019).

- BRENES CORTÉS, J., "Nueva suspensión legal del controvertido art. 348 bis de la Ley de Sociedades de Capital”, en Justiça do Direito, junio 2014.

- CABANAS TREJO, R., "Dividendo, derecho de separación del socio, nombramiento de experto y cuestiones de táctica registral", en Diario La Ley, núm. 9.412 (2019).

- CÁCERES CÁRCELES, C., "El ejercicio del derecho de separación del socio en caso de no distribución de dividendos. Las reformas introducidas por el art. 348 bis LSC", en Revista de Derecho de los negocios, 263-264 (2012).

- CÁMARA ÁlVAREZ, M. de la, Estudios Jurídicos sobre la Sociedad Anónima, Ed. Civitas, 1995.

- CAMPINS VARGAS, A., "Derecho de separación por no reparto de dividendos: ¿es un reparto disponible por los socios?", en Revista Jurídica Española de Doctrina, Jurisprudencia y Bibliografía, 7824 (2012).

- CAMPINS VARGAS, A., y ALFARO ÁGUILA-REAL, J., Abuso de la mayoría en el reparto de dividendos y derecho de separación del socio en las sociedades de capital. Civitas, 2014.

- CAMPINS VARGAS, A., y ALFARO ÁGUILA-REAL, J., "El abuso de la mayoría en la política de dividendos. Un repaso por la jurisprudencia", en Revista Otrosí, 5 (2011).

- Diario de sesiones del Congreso de los Diputados, Comisión de Economía y Compatitividad, nº 51, 6 y 14 de marzo de 2012. 
- FARRANDO MIGUEL, I., El derecho de separación del socio en la Ley de Sociedades Anónimas y la Ley de Sociedades Limitadas. Ed. Civitas, 1998.

- FERNÁNDEZ DEL POZO, L., "Greenmail y amortización no paritaria de acciones y de participaciones. Un análisis crítico del estado de la cuestión en nuestra jurisprudencia”, en Revista de Sociedades, 21 (2003).

- FRAMIÑÁN SANTAS, J., La exclusión del socio en la sociedad de responsabilidad limitada, Ed. Comares, 2005.

- GONZÁLEZ CASTILLA, F., "Reconocimiento del derecho de separación en caso de falta de distribución de dividendos (introducción del nuevo art. 348 bis LSC)", en GONZÁLEZ CASTILLA; RODRÍGUEZ ARTIGAS, y FARRANDO MIGUEL, Las reformas de la Ley de Sociedades de Capital, Ed. Aranzado, 2012.

- HERNANDO CEBRIÁ, L., El abuso de la posición jurídica del socio en las sociedades de capital, Ed. Bosch, 2013.

- ILLESCAS ORTIZ, J., "Reparto obligatorio de dividendos en sociedades no cotizadas", en Diario Expansión, 29 de septiembre de 2011.

- ILLESCAS ORTIZ, R.,"El derecho del socio al dividendo hoy: apunte”, en Revista de Derecho de los Negocios, 21 (1992).

- JUSTA MENCÍA, J., "La empresa familiar ante el nuevo derecho de separación por falta de dividendos", en web de Gómez Acebo\&Pombo, Septiembre 2011.

- MARTÍNEZ MUÑOZ, M., "Entre el abuso de la mayoría y el de minoría en la política de distribución de dividendos: a propósito del "nuevo" artículo 348 bis de la Ley de sociedades de capital", en Revista de Derecho de Sociedades, 55 (2019).

- MARTÍNEZ SANZ, F., "Causas de separación del socio en la Ley de Sociedades de Responsabilidad Limitada", en Revista de Derecho de Sociedades, Año IV, ${ }^{\circ} 6$ (1996).

- NEILA HERNÁNDEZ, J.L., La Ley de Sociedades de Responsabilidad Limitada de 1995. Doctrina, jurisprudencia y Directivas Comunitarias, Ed. Civitas, Universidad de Jaén, 1996.

- PAZ-ARES RODRÍGUEZ, C., "Aproximación al estudio de los squeeze-outs en el derecho español”, en Revista de Derecho Bancario y Bursátil, 91 (2003). 
- PAZ-ARES RODRÍGUEZ, C., "Las sociedades mercantiles", en MENÉNDEZ, A., Lecciones de Derecho Mercantil, Ed. Thomson/ Aranzadi' 2005.

- ROJO FERNÁNDEZ-RÍO, Á.,"La sociedd de responsabilidad limitada: problemas de política y técnica legislativas", en BONARDELL LENZANO, R.; MEJÍAS GÓMEZ, J, y NIETO CAROL, U. (coords.), La Reforma de la Sociedad de Responsabilidad Limitada, Ed. Dyckinson, 1994.

- SÁNCHEZ ANDRÉS, A., "La acción y los derechos del accionista", en Comentario al régimen legal de las sociedades mercantiles, Madrid 1994, t. IV.

- SÁNCHEZ CALERO, FERNANDO Y SÁNCHEZ-CALERO GUILARTE, JUAN. "Instituciones de Derecho Mercantil". Volumen I, Ed. Thomson Aranzadi, 2007. 30ª edición.

- URÍA y GARRIGUES, Comentario a la Ley de Sociedades Anónimas, 1976, t. II.

- URÍA, R., Derecho Mercantil, Ed. Marcial Pons, ${ }^{25} 1998$.

- VÁZQUEZ CUETO, J.C., "La sociedad anónima: las cuentas y la documentación contable en la sociedad anónima", en OLIVENCIA, M.; FERNÁNDEZ-NÓVOA, C., y JIMÉNEZ DE PARGA, R., Tratado de Derecho Mercantil, Ed. Marcial Pons, 2001. 
